\title{
Zília OSÓRIO DE CASTRO, João ESTEVES, Natividade
} MONTEIRo (dir.) Mulheres na $1^{\underline{a}}$ República. Percursos, Conquistas e Derrotas | Teresa PINTo (dir.), Percursos, Conquistas e Derrotas das Mulheres na $1^{\underline{a}}$ República Lisbonne, Éditions Colibri, 2011, 376 p. | Lisbonne, CML, 2010, 150 p.

\section{Sónia Ferreira}

\section{(2) OpenEdition}

\section{Journals}

Édition électronique

URL : http://journals.openedition.org/clio/12692

DOI : $10.4000 /$ clio. 12692

ISSN : $1777-5299$

Éditeur

Belin

Édition imprimée

Date de publication : 1 décembre 2015

Pagination : 309-309

ISBN : 9782701194325

ISSN : 1252-7017

Référence électronique

Sónia Ferreira, «Zília osório de CASTRo, João esteves, Natividade monteiro (dir.) Mulheres na $7^{a}$ República. Percursos, Conquistas e Derrotas | Teresa pinto (dir.), Percursos, Conquistas e Derrotas das Mulheres na $7^{a}$ República », Clio. Femmes, Genre, Histoire [En ligne], 42 | 2015, mis en ligne le 14 janvier 2016, consulté le 23 septembre 2020. URL : http://journals.openedition.org/clio/12692 ; DOI : https:// doi.org/10.4000/clio.12692

Ce document a été généré automatiquement le 23 septembre 2020.

Tous droits réservés 


\section{Zília OSÓRIO DE CASTRO, João ESTEVES, Natividade MONTEIRO (dir.) Mulheres} na $1^{\underline{a}}$ República. Percursos, Conquistas e Derrotas | Teresa PINTO (dir.), Percursos, Conquistas e Derrotas das Mulheres na $1^{\underline{a}}$ República

Lisbonne, Éditions Colibri, 2011, 376 p. | Lisbonne, CML, 2010, 150 p.

\section{Sónia Ferreira}

\section{RÉFÉRENCE}

Zília Osório de Castro, João Esteves, Natividade Monteiro (dir.) Mulheres na $1^{\underline{a}}$ República. Percursos, Conquistas e Derrotas, Lisbonne, Éditions Colibri, 2011,376 p. | Teresa Pinto (dir.), Percursos, Conquistas e Derrotas das Mulheres na $1^{\underline{a}}$ República, Lisbonne, CML, 2010, $150 \mathrm{p}$.

1 Voici deux ouvrages collectifs qui portent sur le rôle des femmes portugaises dans la période qui couvre la fin de la monarchie et la proclamation de la République, le 5 octobre 1910. Complémentaires par les travaux sur les questions de genre qu'ils réunissent, ils ont aussi en commun le moment de leur parution, au lendemain des commémorations du centenaire de l'instauration de la République au Portugal, date qui a donné lieu à de nombreux colloques, conférences et expositions.

2 Chacun d'eux a été organisé par les participants d'un projet de recherche en cours, Faces de Eva. Estudos sobre Mulheres [Visages d'Eva. Études sur les femmes], porté par le Centro de Estudos de Sociologia [Centre d'Études en Sociologie] de la Universidade Nova de Lisboa. Le premier rassemble quatorze contributions; le second est le 
catalogue d'une exposition qui s'est tenue au Museu República e Resistência [Musée de la République et de la Résistance] de Lisbonne et réunit dix-huit textes et des matériaux d'archives sélectionnés par les auteurs qui sont aussi, pour la plupart d'entre eux, des contributeurs du premier livre. Ainsi, les thèmes et les sous-thèmes étudiés se recoupent dans les deux ouvrages, même s'ils sont analysés bien plus en profondeur dans le premier que dans le second; celui-ci se caractérise davantage par l'importance considérable de l'iconographie présentée, parmi lesquels, entre autres documents historiques, des articles de presse et des échanges épistolaires.

3 La période étudiée est particulièrement complexe et intéressante pour l'histoire du Portugal. Elle correspond à un temps de transition qui voit l'altération du modèle politique à l'œuvre et un processus de transformation au cours duquel on assiste à l'opposition entre les anciens et les nouveaux modèles, ainsi qu'à l'effacement ou à la métamorphose de ce qui a prévalu jusque-là. Au-delà de ces processus, des faits et des actions qui ont eu lieu, on trouve surtout dans ces deux livres une analyse des acteurs qui y ont pris part, parmi lesquels les femmes portugaises qui, à l'époque, ont joué un rôle actif dans la vie politique, sociale et civique, et qui se sont battues pour des idées et des modèles. Ces ouvrages d'histoire des femmes s'emploient à éclairer les multiples aspects du rôle des femmes durant cette période, notamment leur entrée dans la vie politique, ainsi que la place des hommes et leur relation au féminisme. L'univers étudié tire sa spécificité de ce qu'il est avant tout constitué de femmes et d'hommes du monde intellectuel qui appartenaient à l'élite, bourgeoise ou aristocratique et qui ont été des libéraux, des républicains ou des monarchistes conservateurs. En outre, ce processus n'a pas commencé le 5 octobre 1910, mais plonge ses racines dans le xIX siècle quand se développent les luttes et les revendications portées par les femmes et que grandit leur intervention dans l'espace public pour défendre leurs droits, quelles que soient leurs positions sur l'échiquier politique ou idéologique.

Chaque ouvrage entend aussi lever le voile sur ce que le monde académique peut avoir longtemps caché; il veut contribuer à un domaine d'études qui en est encore à ses débuts au Portugal, où l'analyse du rôle des femmes et de leur contribution à la construction du régime républicain, ainsi que de leur opposition à ce dernier, est fréquemment négligée. Cela tient notamment à ce que ce thème reste encore très lié au militantisme féministe qui veut parfois mettre surtout en évidence les contributions exceptionnelles aux processus d'émancipation des femmes. Les articles réunis dans ces deux livres se tiennent à l'écart de positionnements unilatéraux en discutant aussi des luttes de femmes monarchistes et/ou catholiques, même s'il est avant tout question des élites urbaines et intellectuelles et s'il n'est fait que quelques références au monde rural et aux classes populaires, pensés comme récepteurs plus que comme acteurs de ces processus.

5 Les articles portent sur des questions très variées qui se posent aussi bien au Portugal que dans d'autres contextes nationaux, ce qui permet des comparaisons intéressantes. Parmi les thèmes abordés figurent la relation entre les femmes militantes et les partis ou mouvements de l'époque, au premier rang desquels le Parti républicain et la francmaçonnerie, les images des femmes dans les discours féministes et antiféministes, les conduites déviantes et l'anomie sociale (la femme marginale: la prostituée, la criminelle, l'adultère, l'homosexuelle), la coexistence de différents féminismes (leurs dirigeantes, leurs institutions), la façon dont les différents régimes républicains ont géré la question du genre, la capacité d'intervention croissante des femmes et leurs 
réseaux internationaux. D'autres questions centrales sont également abordées : le droit de vote, le pacifisme, l'anticléricalisme, ainsi que le patriotisme et le nationalisme, surtout à la veille et pendant la Première Guerre mondiale. La participation du Portugal à la Grande Guerre a offert aux femmes l'occasion d'obtenir des droits sociaux et surtout de participer à la vie publique, notamment lorsqu'ont été créées des organisations d'aide aux soldats portugais. On y trouvera encore des thématiques transversales comme le mouvement associatif ou le monde du travail (les différences salariales, les protestations contre la présence des femmes sur le marché de travail et l'interdiction de travailler dans certains secteurs professionnels), qui sont discutées de manière générale ou dans des contextes spécifiques. Le théâtre et les beaux-arts (dont le cinéma et la critique littéraire et artistique) sont aussi évoqués, à travers les textes, les auteurs, les thématiques, les conditions de travail, l'enseignement, la propagande et les relations avec le régime dans le premier ouvrage, à travers les expositions, leurs thèmes et l'internationalisation dans le second.

Les féministes portugaises ont participé aux mouvements d'opposition et de résistance pour lesquels elles ont été emprisonnées ou exilées, ainsi que les femmes qui ont participé à des soulèvements dans le monde rural contestant l'expropriation des biens de l'Église et la laïcisation de l'espace public et de l'enseignement. Sont également étudiés les hommes qui ont réfléchi sur les féminismes et les antiféminismes. Ces acteurs et actrices se trouvent au centre d'un monde fait aussi bien de luttes et de convictions profondes que de stéréotypes, d'accusations et de contradictions (par exemple, dans la relation avec l'Église catholique, les discussions sur l'avortement, l'enseignement ou les lois du travail) qui nous permettent d'observer une réalité dans sa complexité intrinsèque et ses ambivalences.

On regrettera toutefois, de façon générale, que certains articles ne présentent pas des conclusions plus élaborées et plus critiques d'un point de vue analytique. Mais il n'en reste pas moins, pour reprendre les termes de Fernando Catroga qui signe la préface du premier de ces deux livres, qu'il s'agit là de points de départ substantiels ouvrant sur de nombreuses pistes à prolonger, en raison surtout, de notre point de vue, de l'hétérogénéité des thèmes soulevés.

\section{AUTEURS}

\section{SÓNIA FERREIRA}

Centro em rede de investigaçao em antropologia (SCTE - Insituto Universitário de Lisboa) URMIS - Paris 7 